\title{
The penile ultrasound study: an unnecessary exam or an ace in the hole?
}

(c) The Author(s), under exclusive licence to Springer Nature Limited 2021

IJIR: Your Sexual Medicine Journal (2022) 34:505-506; https://doi. org/10.1038/s41443-021-00473-0

Penile ultrasound (PU) is a second-level diagnostic test that can be used for the assessment of hemodynamic and echo-structural features of the penis, whose first description dates back to about 50 years ago [1]. At present, different pathological conditions that alter the echo structure of the organ [including Peyronie's disease (PD), penile fractures, and tumors] can be studied in detail by PU [2]. Furthermore, a dynamic duplex study (DDS) is mainly dedicated to evaluate the integrity of the vascular mechanism in patients with erectile dysfunction (ED), especially when a potential vasculogenic etiology of ED is suspected (e.g., diabetes mellitus, renal transplantation, multiple concomitant CV risk factors and/or overt peripheral vascular disease, and poor responders to oral therapy) [3].

\section{PU IN ED ASSESSMENT}

In-office evaluation of ED by PU may benefit the decision-making process in regard to choosing the most appropriate treatment, something that assumes an important role in the era of tailored therapy. Unfortunately, although there have been attempts to establish standard operating procedures for DDS [4], many questions still remain unresolved. Can we rely on the assessment in basal conditions (flaccid penis) or is pharmacologically induced erection always necessary? If so, which drug or combination and especially with which dose is it best to use? Is a redosing useful in order to achieve maximal cavernosal smooth muscle relaxation and possibly full erectile response in anxious patients who do not achieve a maximum erection? Can audiovisual sexual stimulation be of help to increase sexual arousal and potentially lead to lower rates of false diagnoses? Moreover, are the peak systolic velocity (PSV), end-diastolic velocity (EDV), and resistive index (RI) the main parameters on which to base the diagnosis and how much can the interoperator variability affect the data interpretation?

The ideal procedure to assess the penile vascular integrity is PU with pharmacologically induced erections. For this purpose, an intracavernous injection of vasoactive agents is currently the gold standard method and the most commonly used agent is prostaglandin E1 (PGE1) at the dose of $10 \mathrm{mcg}$ [4].

However, a recent study showed that Trimix 0.25 cc (a mix of papaverine, PGE1, and phentolamine) offers an advantage over PGE1 alone for the diagnosis of vasculogenic ED, because of its effectiveness in promoting complete smooth muscle relaxation and providing a more potent response [5].

$\mathrm{PSV}>30 \mathrm{~cm} / \mathrm{s}, \mathrm{EDV}<3 \mathrm{~cm} / \mathrm{s}$, and $\mathrm{RI}>0.8$ are considered normal [3], while patients presenting with PSV $<25 \mathrm{~cm} / \mathrm{s}$ are considered as affected with arterial insufficiency. Venous occlusive dysfunction is usually defined as PSV $>30 \mathrm{~cm} / \mathrm{s}$ with EDV $>6 \mathrm{~cm} / \mathrm{s}$ and $\mathrm{RI}<0.6$ [6]. There are however different ultrasonographic criteria to consider the presence of a venogenic ED. The detection of continuous blood flow signals in the deep dorsal vein, peak velocity greater than $3 \mathrm{~cm} / \mathrm{s}$, PSV greater than $30 \mathrm{~cm} / \mathrm{s}$, and EDV greater than $5 \mathrm{~cm} / \mathrm{s}$ seem to be the criteria that best relate to cavernosography findings, with the highest sensitivity (91.7\%) and the highest accuracy (84.9\%) [7].

Anxiety or insufficient dose may lead to incomplete relaxation, thus leading to a false diagnosis, and redosing might be needed; however, there is no consensus on what the ideal drug and dose is to use [8].

\section{PU IN PD ASSESSMENT}

The diagnosis of PD is based on the patient's medical history and physical examination in the majority of cases. However, PU plays an important role in the assessment of some important clinical aspects of patients with PD which may be relevant to the clinical management of the single case [9].

Firstly, it is not uncommon to find a subject in whom it is not possible to detect the presence of a plaque on physical examination, while at the ultrasound study the presence of isolated septal scarring (ISS) and punctate scarring (PS) can be detected. In a cohort study of 722 patients undergoing PU for PD or ED, Punjani et al. found that $30 \%$ of the patients had ISS and $27 \%$ had PS [10]. Patients with ISS and PS can present with ED, loss of penile length, and priapism, and without resorting to a thorough PU examination the etiology of the symptoms may remain elusive.

Secondly, the presence of calcifications within plaques is also an important finding in the evaluation and management of the PD patient. Calcified plaques have been found to respond poorly to medical treatment and are unlikely to spontaneously resolve [11].

PU shows $\sim 100 \%$ sensitivity for detecting gross plaque calcifications [7], giving the clinician valuable information that can aid in directing management as well as setting patient expectations early in the course of the disease.

Thirdly, PD can be associated with the presence of ED, either as a simple concomitant situation or through a causal link between the two conditions. In fact, in case of evolution of the PD, a progressive extension of the fibrosis to the smooth muscle of the corpora or the media of penile arteries can occur, leading to venoocclusive dysfunction or to arteriogenic ED, respectively [11]. In this scenario, a detailed DDS can be of support in defining the vascular involvement and the extent of damage.

\section{Clinical considerations}

From what has been said it seems clear that the use of PU has very specific areas of application in which it can become a key element for a correct and detailed classification but above all a correct management of the patient. We give two examples of all: (1) the patient with vasculogenic ED who can be managed with an etiological therapy by combining low-intensity shockwave therapy 
(LiST) with drug therapy and (2) the patient with PD who must opt for management with conservative (intralesional therapy) or surgical treatment, and in the latter case, receive the correct information on the various available solutions.

But if we take a look at further concrete applications that will surely find space in the not too distant future, there are the use of $\mathrm{PU}$ as a follow-up tool for patients with vasculogenic ED treated with LiST [12] and then the application of ultrasonic shear wave elastography as potential reliable and objective clinical imaging index indicator for evaluating penile hardness [13].

Finally, it is evident that PU is a diagnostic test that we could define as "ultraspecialized," to which we must devote extreme attention in order to achieve adequate quality standards both in the execution and in the interpretation of the results. For instance, there are possible interfering factors, such as the environmental situation, the machine used and its setting, and the assessment of degree of tumescence and rigidity, which although apparently secondary, are of fundamental importance for the perfect adequacy of the exam. Only an adequately trained specialist can meet these requirements, and in our view, ultraspecialized training in this sense is a crucial point to which present and future uro-andrologists cannot fail to dedicate themselves.

Paolo Verze (iD ${ }^{1 凶}$, Mario Belmonte (iD $^{1}$, Tommaso Cai $\left(\right.$ ID $^{2}$ and Javier Romero Otero iD $^{3}$

${ }^{1}$ Department of Medicine, Surgery and Dentistry, Scuola Medica Salernitana, University of Salerno, Salerno, Italy. ${ }^{2}$ Department of Urology, Santa Chiara Regional Hospital, Trento, Italy. ${ }^{3}$ Department of Urology, Instituto de Investigación Sanitaria Hospital 12 de October (imas12), Hospital Universitario 12 October, Madrid, Spain.

凶email: pverze@unisa.it

\section{REFERENCES}

1. Malvar T, Baron T, Clark SS. Assessment of potency with the Doppler flowmeter. Urology. 1973;2:396-400.

2. Wilkins CJ, Sriprasad S, Sidhu PS. Colour Doppler ultrasound of the penis. Clin Radiol. 2003;58:514-23.

3. Salonia A, Bettocchi C, Boeri L, Capogrosso P, Carvalho J, Cilesiz NC, et al. European Association of Urology Guidelines on Sexual and Reproductive Health2021 Update: male sexual dysfunction. Eur Urol. 2021;S0302-2838:01813-3.

4. Sikka SC, Hellstrom WJ, Brock G, Morales AM. Standardization of vascular assessment of erectile dysfunction: standard operating procedures for duplex ultrasound. J Sex Med. 2013;10:120-9.
5. Said SZ, Nasser TA, Ayad M, Motawi AT. Evaluation of the sensitivity of different doses of vasoactive drugs in diagnosing erectile dysfunction in impotent patients: a prospective case-control study. Cent Eur J Urol. 2021;74:109-15.

6. Ma M, Yu B, Qin F, Yuan J. Current approaches to the diagnosis of vascular erectile dysfunction. Transl Androl Urol. 2020;9:709-21.

7. Chen L, Xu L, Wang J, Li H, Zhang D, Zhang $C$, et al. Diagnostic accuracy of different criteria of pharmaco-penile duplex sonography for venous erectile dysfunction. J Ultrasound Med. 2019;38:2739-48.

8. Cannarella R, Calogero AE, Aversa A, Condorelli RA, La Vignera S. Differences in penile hemodynamic profiles in patients with erectile dysfunction and anxiety. J Clin Med. 2021;10:402.

9. McCauley JF, Dean RC. Diagnostic utility of penile ultrasound in Peyronie's disease. World J Urol. 2020;38:263-8.

10. Punjani N, Stern N, Brock G. Characterization of septal and punctate scarring in Peyronie's disease. Urology. 2018;118:87-91.

11. Bekos A, Arvaniti M, Hatzimouratidis K, Moysidis K, Tzortzis V, Hatzichristou D. The natural history of Peyronie's disease: an ultrasonography-based study. Eur Urol. 2008;53:644-50.

12. Kalyvianakis D, Mykoniatis I, Memmos E, Kapoteli $P$, Memmos D, Hatzichristou D. Low-intensity shockwave therapy (LiST) for erectile dysfunction: a randomized clinical trial assessing the impact of energy flux density (EFD) and frequency of sessions. Int J Impot Res. 2020;32:329-37.

13. Cheng $H$, Niu Z, Xin F, Yang L, Ruan L. A new method to quantify penile erection hardness: real-time ultrasonic shear wave elastography. Transl Androl Urol. 2020;9:1735-42.

\section{AUTHOR CONTRIBUTIONS}

All authors participated sufficiently in the work to take responsibility for all the content and have given final approval of the submitted manuscript. PV: paper conception, paper drafting, and paper revision. MB: literature search and abstract and full-text selection. TC: abstract and full-text selection and paper revision. JRO: paper drafting and paper revision.

\section{COMPETING INTERESTS}

The authors declare no competing interests.

\section{ADDITIONAL INFORMATION}

Correspondence and requests for materials should be addressed to Paolo Verze.

Reprints and permission information is available at http://www.nature.com/ reprints

Publisher's note Springer Nature remains neutral with regard to jurisdictional claims in published maps and institutional affiliations. 